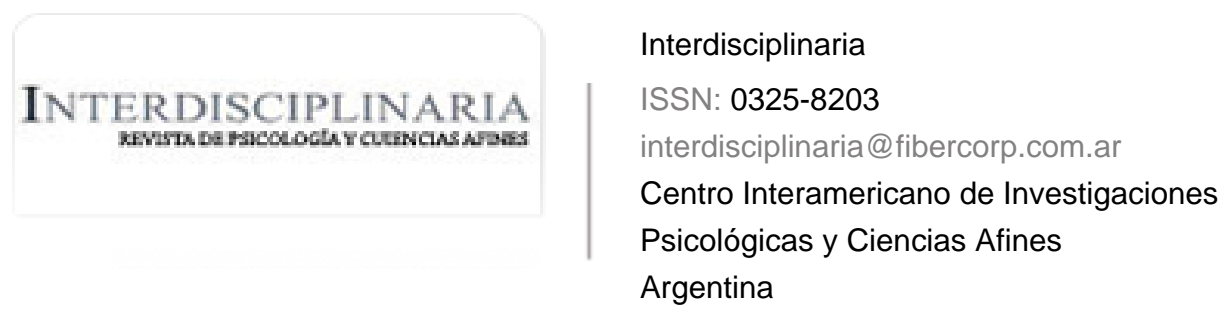

JUSTEL, NADIA; O'CONOR, JAIME; RUBINSTEIN, WANDA MODULACIÓN DE LA MEMORIA EMOCIONAL A TRAVÉS DE LA MÚSICA EN ADULTOS MAYORES: UN ESTUDIO PRELIMINAR Interdisciplinaria, vol. 32, núm. 2, 2015, pp. 247-259 Centro Interamericano de Investigaciones Psicológicas y Ciencias Afines Buenos Aires, Argentina

Disponible en: http://www.redalyc.org/articulo.oa?id=18043528003

Cómo citar el artículo

Número completo

- Más información del artículo

- Página de la revista en redalyc.org

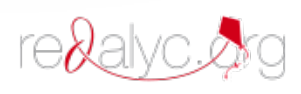

Sistema de Información Científica Red de Revistas Científicas de América Latina, el Caribe, España y Portugal Proyecto académico sin fines de lucro, desarrollado bajo la iniciativa de acceso abierto 


\title{
MODULACIÓN DE LA MEMORIA EMOCIONAL A TRAVÉS DE LA MÚSICA EN ADULTOS MAYORES: UN ESTUDIO PRELIMINAR
}

\author{
MODULATION OF EMOTIONAL MEMORY THROUGH MUSIC IN OLDER ADULTS: A \\ PRELIMINARY STUDY
}

\author{
NADia JusteL*, Jaime O’CONOR** Y WANDA RUBINSTEIN*** \\ *Doctora en Psicología. Miembro de la Carrera del Investigador Científico del Consejo Nacional de Investigaciones \\ Científicas y Técnicas (CONICET). E-Mail: nadiajustel@gmail.com \\ Laboratorio de Psicología Experimental y Aplicada (PSEA). Instituto de Investigaciones Médicas (IDIM). \\ **Licenciado en Psicología. Profesor Adscripto de la Cátedra Neuropsicología Cognitiva en la Facultad de Psicología \\ de la Pontificia Universidad Católica Argentina (UCA). E-Mail: jaimeoconor@gmail.com \\ ***Doctora en Psicología. Miembro de la Carrera del Investigador Científico del Consejo Nacional de Investigaciones \\ Científicas y Técnicas (CONICET) e Investigadora Asistente en el Laboratorio de Deterioro Cognitivo del Servicio de \\ Neurología del Hospital Interzonal General de Agudos (HIGA) Eva Perón. E-Mail: wrubinstein@live.com.ar
}

\section{RESUMEN}

Existen múltiples factores que pueden afectar la consolidación de la memoria de los eventos emocionales, fortaleciendo o deteriorando los recuerdos. Distintas investigaciones en neurociencia han demostrado que el nivel de arousal puede tener un efecto determinante en el almacenamiento y consolidación de la memoria. Además, las investigaciones señalan que la exposición a diferentes piezas musicales puede modular la memoria, ya sea aumentándola o disminuyéndola; sin embargo, no se encuentran estudios realizados hasta el momento con adultos mayores. El objetivo del trabajo realizado fue evaluar cómo diferentes estímulos auditivos, piezas musicales activantes y relajantes, así como ruido blanco como condición control, modulaban la consolidación de la memoria en adultos mayores. Participaron 27 sujetos, divididos en tres grupos experimentales, quienes observaron imágenes emocionales o neutras y evaluaron el grado de activación / emocio- nalidad que les producían. De manera inmediata y de acuerdo al grupo de tratamiento asignado, fueron expuestos a diferentes estímulos musicales: música activante y relajante para los grupos experimentales y ruido blanco para el grupo control. Luego se realizaron pruebas de recuerdo libre y reconocimiento de las imágenes, de forma inmediata y diferida (una semana después). Los resultados muestran que los sujetos expuestos a música relajante tuvieron un menor recuerdo y reconocimiento, mientras los que estuvieron expuestos a música activante mostraron un mejor rendimiento. Los hallazgos permiten concluir que la música modula la consolidación de la memoria emocional visual en adultos mayores, siendo la música una herramienta de gran utilidad para la estimulación de la memoria en poblaciones con o sin disfunciones mnésicas.

Palabras clave: Memoria; Música; Emoción; Modulación; Adultos mayores. 


\section{ABSTRACT}

In the last decades, different neuroscientific investigations have shown that emotions can be determinant in memory storage and consolidation. Events with emotional content are remembered more easily than neutral events. There are several factors that could affect memory consolidation for emotional events, strengthening or deteriorating them. Stress is one of them, since investigations indicate that moderate levels of stress improve the memory of emotional events, while high or low levels have the opposite effect (Justel, Psyrdellis, \& Ruetti, 2013, 2014). Multiple studies showed that the exposition to different musical pieces could modulate memory. Activating music, both positive and negative valence, increases de levels of arousal and strengthen memory consolidation (Judde \& Rickard, 2010), while relaxing music has the opposite effect and deteriorate the capacity of emotional memory (Rickard, Wing Wong, \& Velik, 2012). However, there are not studies with older adults. The goal of this study was to evaluate how different musical pieces, arousing and relaxing ones, modulate memory consolidation in older adults. 27 participants were included, divided in three groups. 12 slides with emotional content and 12 neutral were presented in a computer, selected from the International Affective Picture System (Lang, Bradley, \& Cuthbert, 1995). The older adults watched the emotional and neutral images, and evaluated the arousal /emotionality degree of the images as they filled in a table of five choices, from not exciting to very exciting. According to the assignment group, they were exposed to different musical stimuli: activating or relaxing music for the experimental groups or white noise in the control group. The auditive stimulies were selected according to the previous literature. For the activating musical stimuli, Symphony No. 70 in D major of Joseph Haydn was chosen (Kreutz, Ott, Teichmann, Osawa, \& Vaitl, 2008); for the relaxing musical stimuli, Pachebel's canon in D major was chosen (Knight \& Rickard, 2001); for the control stimuli, white noise was chosen (Rickard et al., 2012). Then free recall and recognition test were performed, immediately and deferred (one week later). In free recall, each subject briefly listed the images he remembered, mentioning them with a word or a short sentence. For the recognition test, the 24 images were mixed up with 24 new images, and the participants had to indicate if they had seen each image or not, as they filled in a table. Regarding to the evaluation of the arousal / emotionality degree of the images, the results indicate that older adults, no matter the group, punctuated the emotional images as more activating tan neutral images, consolidating, as other studies, the validity and reliability of IAPS. The participants exposed to relaxing music had a worse performance in free recall and recognition, compared with the other two groups. On the other hand, it was expected that participants exposed to activating music have a better performance in free recall and recognition test. In free recall, both immediate and deferred, there is a tendency for the activating group to perform better than the control group, but no significant statistical data was found. Regarding to the recognition test, both immediate and deferred, no significant differences were found between the activating and the control groups. This may be because the sample was formed by a reduced number of participants, but if the sample is extended, the results may change. These results allow to conclude that music modulate the consolidation of visual emotional memory in older adults, being music a useful tool in memory stimulation and a possible therapeutic resource for patients with memory dysfunctions.

Key words: Memory; Music; Emotion; Modulation; Older adults.

\section{INTRODUCCIÓN}

La memoria emocional es el resultado del almacenamiento de la información que estuvo acompañada por factores muy estresantes a través de los cuales pudo fijarse con más facilidad (Bermúdez-Rattoni \& Prado-Alcalá, 2001; Justel \& Psyrdellis, 2014; Ruetti, Justel \& Bentosela, 2009). En las últimas décadas, distintas investigaciones en neurociencia 
han demostrado que las emociones pueden tener un efecto determinante en el almacenamiento y consolidación de la memoria (SolísVivanco, 2012). Por ejemplo, Cahill y Mc Gaugh (1995) realizaron un estudio en el que los participantes observaban una serie de diapositivas acompañadas por una historia que las describía. Las diapositivas se dividían en tres fases: la primera y la tercera eran iguales para todos, mientras que la segunda fase era emocionalmente activante para el grupo experimental y neutral para el grupo control. Los sujetos del grupo experimental recordaron más detalladamente las diapositivas e historias de la fase emocionalmente activante que el grupo control.

Esto indicaría que los eventos con contenido emocional se recuerdan más fácilmente que los eventos neutrales (Bradley, Greenwald, Petry \& Lang, 1992). Dolcos, LaBar y Cabeza (2004), partiendo de esta evidencia, han demostrado que la memoria tiene un mejor rendimiento ante la exposición de imágenes con contenido emocional, tanto placenteras como displacenteras, que ante imágenes con contenido neutral.

Hay múltiples factores que influyen en la modulación de la memoria. El estrés es uno de ellos, ya que las investigaciones indican que niveles moderados de estrés mejorarían el recuerdo de eventos emocionales, mientras que niveles bajos o elevados tendrían el efecto contrario dando cuenta de una curva de $\mathrm{U}$ invertida (Justel, Psyrdellis \& Ruetti, 2013, 2014). Cahill, Gorski y Le (2003) demostraron que la potenciación en la consolidación de la memoria a partir de la segregación de hormonas de estrés no se da de manera uniforme, sino en relación con el nivel de arousal que se presenta en la codificación inicial del material. Para probar esta hipótesis, se utilizó la técnica de estrés debido a frío (Cold Pressor Stress: CPS). En la misma, los sujetos colocan su brazo en agua helada, lo cual induce la liberación de hormonas de estrés, por ejemplo cortisol. Administraron la CPS o el procedimiento control (inmersión del brazo en agua tibia) a los sujetos, luego de observar diapositivas de variado contenido emocional. Una semana después, los sujetos a quie- nes les fue administrada la CPS, presentaron un aumento significativo en la memoria de las láminas emocionalmente activantes en comparación con el grupo control, pero no en las láminas neutrales.

Otra forma de modular la memoria es mediante la música (Justel \& Rubinstein, 2013). El mecanismo por el cual la música modula la consolidación es igual al que subyace al efecto modulador del estrés. La música activante, tanto de valencia placentera como displacentera, al aumentar los niveles de arousal, potencia la consolidación de la memoria (Judde \& Rickard, 2010), mientras que la relajante, al lograr el efecto contrario, atenúa la capacidad de la memoria emocional (Rickard, Wing Wong \& Velik, 2012). Por ejemplo, la música relajante disminuye la presión arterial y la tasa cardíaca, mientras que la activante presenta el patrón contrario (Knight \& Rickard, 2001).

Las investigaciones realizadas por Rickard y colaboradores (2012) han puesto en evidencia que la música relajante atenúa el recuerdo de la memoria emocional. Específicamente los autores les mostraron a los participantes unas diapositivas las cuales eran acompañadas por una narración neutra $o$ emocionalmente activante y luego de ello, fueron expuestos al tratamiento que consistía en escuchar música relajante. Después de una semana evaluaban tanto recuerdo libre como reconocimiento de las diapositivas y de la historia. Los autores hallaron que la música relajante redujo significativamente la evocación de la narración emocionalmente activante.

Por otra parte, Judde y Rickard (2010) demostraron que la música activante potencia la memoria. Presentaron a los participantes una lista de palabras neutras. Luego de un intervalo de 0, 20 ó 45 minutos los expusieron a música activante de valencia placentera o displacentera. Después de una semana, los participantes fueron evaluados con una prueba de memoria de reconocimiento de palabras. El rendimiento fue superior en los participantes expuestos a la música luego de un intervalo de 20 minutos, más allá de la valencia, pero no inmediatamente ni luego de 45 minutos. 
Es sabido que la memoria declina con la edad, en particular a partir de los 60 años (Horn, 1982; Lezak, 1995; Schaie, 1996). Pero esta declinación no necesariamente implica que se encuentre afectado también el efecto modulatorio que la emoción ejerce en la memoria (Denburg, Buchanan, Tranel \& Adolphs, 2003; Justel \& Ruetti, 2014). Justel y Ruetti (2014) evaluaron el efecto modulatorio de la emoción en la memoria en adultos jóvenes y adultos mayores. Para ello, los participantes observaron 48 imágenes con contenido emocional negativo o neutro; a medida que las observaban valoraban su impacto emocional y luego, de modo inmediato, se evaluó su recuerdo. Se encontró que la retención de las imágenes (tanto emocionales como neutras) era significativamente menor en los adultos mayores que en los jóvenes. Sin embargo, en ambos grupos se mantuvo la valoración del contenido emocional.

De acuerdo a estos antecedentes, el objetivo del estudio que se informa fue evaluar el efecto modulatorio activante y relajante de diversas piezas musicales, sobre la memoria en adultos mayores. De acuerdo a las investigaciones realizadas se conoce que los efectos de ambos no serán iguales. Por lo tanto, se buscó indagar la influencia de los distintos estilos musicales en la consolidación de la información previamente adquirida en una tarea de memoria. Se analizó cómo cada estilo de música facilita, o por el contrario interfiere, en el almacenamiento y evocación de la información.

De esta manera, se buscó evaluar la modulación de la memoria emocional a través de la música. A su vez, de hallarse estas diferencias, ellas podrían tener implicancias para la utilización de la música como posible herramienta terapéutica en pacientes con disfunciones mnemónicas.

\section{MÉTodo}

\section{PARTICIPANTES}

Se seleccionaron como participantes a 27 adultos mayores, 11 hombres y 16 mujeres, con una media de edad de 81 años (rango 7092) y una media de escolaridad de 15 años (rango 12-18). Los mismos desconocían los objetivos de la prueba y fueron asignados aleatoriamente a los diferentes grupos y tratamientos experimentales. No se hallaron diferencias significativas por edad y escolaridad entre los tres grupos experimentales $(p>.05)$.

Se utilizaron como criterios de exclusión antecedentes de enfermedades neurológicas, del desarrollo y trastornos psiquiátricos, presencia de deterioro cognitivo, calculado por una puntuación por debajo de 1.5 desviaciones estándares de la puntuación media, calculado por edad y escolaridad y un puntaje bruto inferior a 24 puntos en el Mini Mental State Examination (Allegri et al., 1999; Butman et al., 2001; Folstein, M., Folstein, S. \& McHugh, 1975).

\section{INSTRUMENTOS}

Se utilizó una computadora con la cual se presentaron a los participantes 12 diapositivas con contenido emocional de valencia positiva y 12 de valencia neutra, que fueron seleccionadas del Sistema Internacional de Imágenes Afectivas (IAPS por sus siglas en inglés, Lang, Bradley \& Cuthbert, 1995). Siguiendo la clasificación de Lang y colaboradores (1995), las mismas variaban en el nivel de activación (arousal, desde 2.95 a 6.36) o de la valencia (valencia, desde 1.97 a 4.93) que contenían.

Se utilizaron cuatro cuestionarios: uno para recolectar los datos sociodemográficos de los participantes, otro de evaluación de emocionalidad, un tercero de recuerdo libre de las imágenes y por último el de reconocimiento de los estímulos.

El cuestionario de datos sociodemográficos contenía los siguientes ítemes a completar: edad, sexo, ocupación, grado de educación académica, antecedentes psiquiátricos, tratamiento psiquiátrico actual y enfermedades relevantes.

La emocionalidad se evaluó con una grilla de 24 ítemes, referidos a las 24 imágenes que fueron presentadas a los sujetos y que ellos 
debían evaluar, según el nivel de emoción percibido con una una escala de 5 puntos (1: Nada emocionante a 5: Muy emocionante).

En el Cuestionario de Recuerdo Libre de Imágenes, cada sujeto enumeró brevemente las que recordaba haber visto, mencionándolas con una palabra o una frase corta.

La planilla de reconocimiento de estímulos consistía en una grilla de 50 ítemes, que contenían las 50 imágenes. Los sujetos marcaban con una cruz las que recordaban haber visto previamente, o bien dejaban el espacio en blanco si no la recordaba. En las 50 imágenes se encontraban incluidas las 24 originales, intercaladas con 26 novedosas.

\section{ESTIMULOS SONOROS}

De acuerdo a los efectos fisiológicos que la música tiene en los sujetos, Wigram, Pedersen y Blonde (2002) definieron los parámetros para determinar si una pieza musical tiene efectos activantes o relajantes. Los elementos musicales que influyen a un efecto estimulante son los siguientes: cambios impredecibles en el tempo, cambios impredecibles o súbitos en volumen, ritmo, timbre, afinación (alturas) o armonía, amplias variaciones en la textura de la música, disonancias inesperadas, acentos inesperados, timbres duros, falta de la estructura y de la forma musical, accelerandos, ritardandos, crescendos y diminuendos inesperados y cortes inesperados en la música. Por otro lado, los elementos musicales que influyen a un efecto relajante son: tempo estable, estabilidad o cambios graduales en volumen, ritmo, timbre, afinación o altura y armonía, textura consistente, modulación armónica predecible, cadencias apropiadas, líneas melódicas predecibles, repetición del material, estructura y forma, timbre suave y pocos acentos. Debido a estas diferenciaciones en estructura y formas musicales se utilizaron tres estímulos auditivos, uno para cada grupo. Para el estímulo musical activante se utilizó la Sinfonía número 70 en D mayor, de Joseph Haydn (Kreutz, Ott, Teichmann, Osawa \& Vaitl, 2008), para el relajante el Canon en D mayor de Pachebel (Knight \& Rickard, 2001), mientras que el estímulo para el grupo control fue ruido blanco (Rickard et al., 2012).

\section{Procedimiento}

El estudio se dividió en dos sesiones individuales con una semana de intervalo entre ambas.

\section{PRIMERA SESIÓN}

Se solicitó a los participantes el consentimiento informado para realizar la prueba y se aseguró la confidencialidad de los resultados de acuerdo a las normas éticas vigentes. Luego se completó el cuestionario de datos sociodemográficos. En tercer lugar, se les administró el Mini Mental State Examination (Allegri et al., 1999).

A continuación se presentaron las 24 imágenes de las IAPS durante 10 segundos cada una. A medida que observaba las imágenes, el participante le indicaba al experimentador cuánta emoción le producían las mismas y se completaba la planilla de evaluación de emocionalidad de las imágenes.

Inmediatamente después, los participantes fueron expuestos durante 2 minutos al estímulo auditivo correspondiente, de acuerdo al grupo al que habían sido asignados: música activante o relajante a los dos grupos experimentales y ruido blanco al grupo control.

Finalmente, se hizo una evaluación inmediata de la memoria. En primer lugar, se completó la hoja de recuerdo libre de las imágenes. Luego se presentaron las 50 imágenes, mientras se completaba la planilla de reconocimiento de los estímulos.

\section{SEGUNDA SESIÓN}

Se realizó una evaluación diferida de la memoria. Se completó otra hoja de recuerdo libre de las imágenes. A continuación se presentaron las 50 imágenes, siendo las 26 imágenes novedosas distintas a las de la primera sesión y mientras, se completó otra planilla de reconocimiento. 
ANÁLISIS DE DATOS

Se chequeó la normalidad y homogeneidad de variancias mediante las pruebas de Shapiro-Wilk y Levene. Los resultados indicaron que ambos supuestos no se cumplieron, por lo cual se realizaron pruebas no paramétricas para analizar los resultados.

Se utilizó la $U$ de Mann-Whitney con un valor de Alpha en .05 para una distribución bilateral, para analizar diferencias entre los grupos. Es decir que se usó este estadístico para una comparación intergrupo en las medidas de emocionalidad así como de recuerdo libre y reconocimiento, para la comparación de las imágenes emocionales por un lado y de las imágenes neutras por otro.

Mientras se realizó el test de Wilcoxon para comparar un mismo grupo en las medidas relacionadas ordinales, es decir, la valoración de emocionalidad (de 1 a 5), recuerdo libre (de 0 a 12) y reconocimiento (de 0 a 12) de imágenes neutras versus imágenes emocionales.

\section{Resultados}

En la evaluación de la emocionalidad los resultados indican que las imágenes emocionales fueron calificadas como más activantes que las neutras en cada grupo $(p<.0001)$, sin encontrarse diferencias entre los grupos en esta escala de valoración $(p>.05)$. Es decir que todos los grupos valoraron como más activantes las imágenes emocionales y como menos excitantes las neutras (ver Gráfico 1).

En relación al recuerdo libre inmediato de las imágenes emocionales, los análisis estadísticos indican que el grupo control se diferencia del grupo relajante $[U(9,8)=11.5$, $p<.02]$ y que el grupo activante se diferencia del grupo relajante $[U(9,8)=9, p<.009]$.

Los demás análisis no mostraron diferencias estadísticamente significativas $(p>.05)$. Es decir que el grupo relajante tuvo un menor recuerdo libre inmediato de las imágenes que los grupos control y activante, quienes a su vez no mostraron diferencias entre ellos (ver Gráfico 2).
En relación al recuerdo libre diferido, el Gráfico 3 parecería indicar que los sujetos expuestos a música activante tendrían un mayor recuerdo de las imágenes emocionales que de las neutras, y un mejor rendimiento en el recuerdo de imágenes emocionales que los grupos relajante y control. Al mismo tiempo, los sujetos expuestos a música relajante parecerían recordar más imágenes neutras que emocionales y tener un mejor rendimiento en el recuerdo de imágenes neutras que el grupo activante y control. Sin embargo, no se encontraron diferencias estadísticamente significativas $(p>.05)$.

En relación al reconocimiento inmediato, el Gráfico 4 muestra el reconocimiento de la totalidad de las imágenes por parte de los tres grupos, así como el reconocimiento de imágenes neutras y emocionales por separado. La $U$ de Mann-Whitney indica que el grupo activante se diferencia del grupo relajante en esta medida $[U(9,8)=16, p<.05]$. No se encontraron diferencias significativas entre los grupos al realizar los análisis separando imágenes emocionales o imágenes neutras $(p>.05)$.

En el reconocimiento diferido (ver Gráfico 5), la medida que abarca la totalidad de las imágenes reconocidas (tanto neutras como emocionales), el grupo control se diferencia del grupo relajante $[U(9,8)=5, p<.003]$.

Por su parte, en el reconocimiento de imágenes neutras el grupo control se diferencia del relajante $[U(9,8)=12.5, p<.03]$ (ver Gráfico 5) y en el reconocimiento de imágenes emocionales nuevamente el grupo control se diferencia estadísticamente del grupo relajante $[U(9,8)=6, p<.005]$ (ver Gráfico 5).

Por otra parte, en el reconocimiento total (imágenes emocionales e imágenes neutras) el grupo activante se diferencia del grupo relajante $[U(9,8)=13, p<.03]$. Ninguno de los otros análisis arrojó diferencias estadísticamente significativas $(p>.05)$.

Estos resultados indicarían que el grupo relajante tuvo un reconocimiento menor de las imágenes tanto neutras como emocionales en comparación al grupo control y al grupo activante. 


\section{Discusión}

El objetivo inicial de este trabajo fue evaluar cómo diferentes piezas musicales, activantes y relajantes, modulaban la consolidación de la memoria en adultos mayores. Se encontraron diversos descubrimientos relevantes. El principal hallazgo indicó que los sujetos expuestos a música relajante presentaron un menor recuerdo y un menor reconocimiento en comparación con los demás grupos.

El IAPS es un sistema de valoración de imágenes que representan un amplio espectro de experiencias ligadas a la vida humana y que evocan un rango de respuestas afectivas normalizadas, con la finalidad de examinar el procesamiento emocional y las influencias afectivas en los procesos cognitivos (Colden, Bruder \& Manstead, 2008). La evaluación de la emocionalidad en el estudio realizado indicó que los adultos mayores puntuaron como más activantes a las imágenes emocionales que a las neutras, consolidando, como tantos otros estudios, la validez y fiabilidad del IAPS.

Una fuente de activación emocional para la modulación de la memoria podría ser la exposición a estímulos musicales (Blood \& Zatorre, 2001; Koelsch, 2010; Koelsch, Fritz, Cramon, Muller \& Friederici, 2006). La música potencia la experiencia emocional evocada por imágenes con contenido afectivo, aumentando o disminuyendo el nivel de arousal (Baumgartner, Esslen \& Jancke, 2006), por lo tanto, tiene la capacidad de modular la consolidación de la memoria (Judde \& Rickard, 2010). La música relajante disminuye el nivel de arousal, y de esta manera, como diversos estudios lo demuestran, atenúa la capacidad de la memoria emocional (Rickard et al., 2012). Los resultados del estudio indican que los sujetos expuestos a música relajante tuvieron un menor recuerdo y reconocimiento en comparación a los otros dos grupos. De esta manera, el estudio que se informa arroja luz acerca del efecto de la música relajante en adultos mayores, resultado que no había sido estudiado hasta el momento.

Por otra parte, se esperaba que los sujetos expuestos a música activante tuvieran un mejor rendimiento tanto en el recuerdo libre y di- ferido, como en el reconocimiento. En el recuerdo libre y diferido puede notarse una tendencia a que el grupo activante tenga un mejor rendimiento que el grupo control, pero no se hallaron datos estadísticamente significativos. Con respecto al reconocimiento de imágenes, tanto inmediato como diferido, no se encontraron diferencias significativas entre el grupo activante y el grupo control. Esto puede deberse a que la muestra estuvo formada por un número reducido de sujetos, pero ampliando la misma los resultados podrían modificarse.

Los estudios que compararon la memoria potenciada por la emoción en adultos jóvenes con adultos mayores demostraron que a pesar de que los adultos mayores presentaron una declinación general de la memoria en relación a los adultos jóvenes, la memoria para los estímulos emocionales sigue siendo superior en comparación a la memoria para los estímulos neutrales, y que el beneficio sigue siendo el mismo en adultos mayores como en los adultos jóvenes (Kensinger, Growdon, Brierley, Medford \& Corkin, 2002). Esto se debe a que la edad no afecta considerablemente las regiones límbicas, incluida la amígdala (Insausti, R., Insausti, A., Sobreviela, Salinas \& Martinez-Penevela, 1998) y por lo tanto no interfiere en la potenciación de la memoria ante estímulos emocionales (Smith et al., 1999). Igualmente hay estudios que desafían este punto de vista ya que los resultados también sugieren que los adultos mayores no tienen una potenciación de la memoria en estímulos neutrales puestos en un contexto emocional. Esto puede deberse a que el envejecimiento produce cambios en el lóbulo frontal, incluyendo deterioro en la sustancia blanca (Double et al., 1996; Raz, Briggs, Marks \& Acker, 1999). Es importante resaltar que no se encuentran en la literatura estudios de modulación de la memoria emocional a través de estímulos musicales específicamente en adultos mayores.

Teniendo en cuenta los hallazgos de la literatura previa en relación a la modulación de la memoria a través de la música y los estudios de la relación entre la memoria y las emociones realizados con adultos mayores, es 
sumamente relevante realizar futuras investigaciones acerca de la música y la memoria emocional en adultos mayores. En primer lugar, ampliar la muestra del estudio que se informa para conocer si hay diferencias significativas ante la exposición de música activante y consolidar los resultados obtenidos con los sujetos expuestos a música relajante. Por otra parte, sería impor- tante realizar estudios con adultos mayores con diferentes patologías, para poder observar si se mantiene el mismo patrón o si se observan diferencias. De esta manera, se podría ampliar y profundizar el conocimiento en el área, como también avanzar con la posible utilización de la música como herramienta terapéutica en patologías que presentan alteraciones en la memoria.

GRÁFICO 1

EMOCIONALIDAD

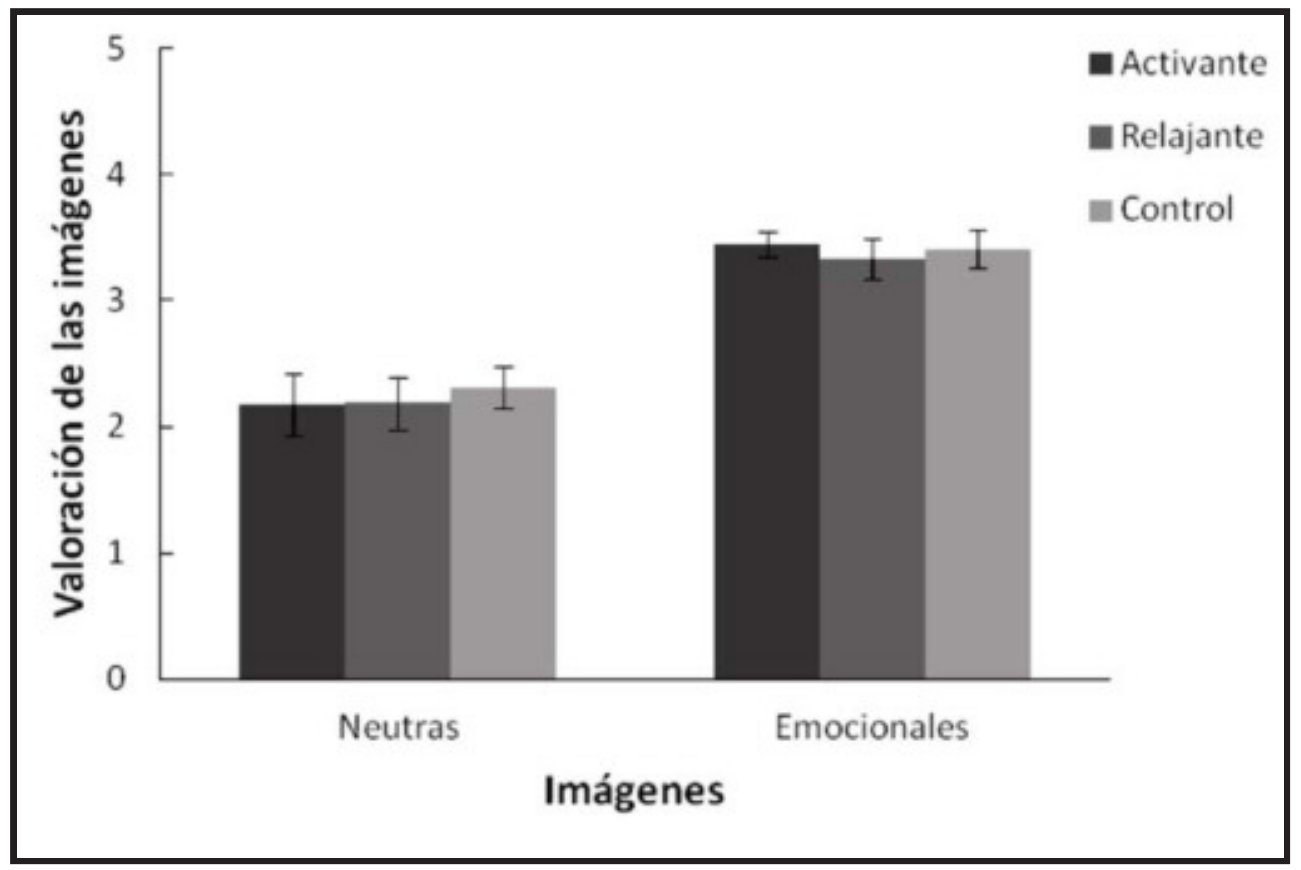


GRÁFICO 2

RECUERDO LIBRE INMEDIATO

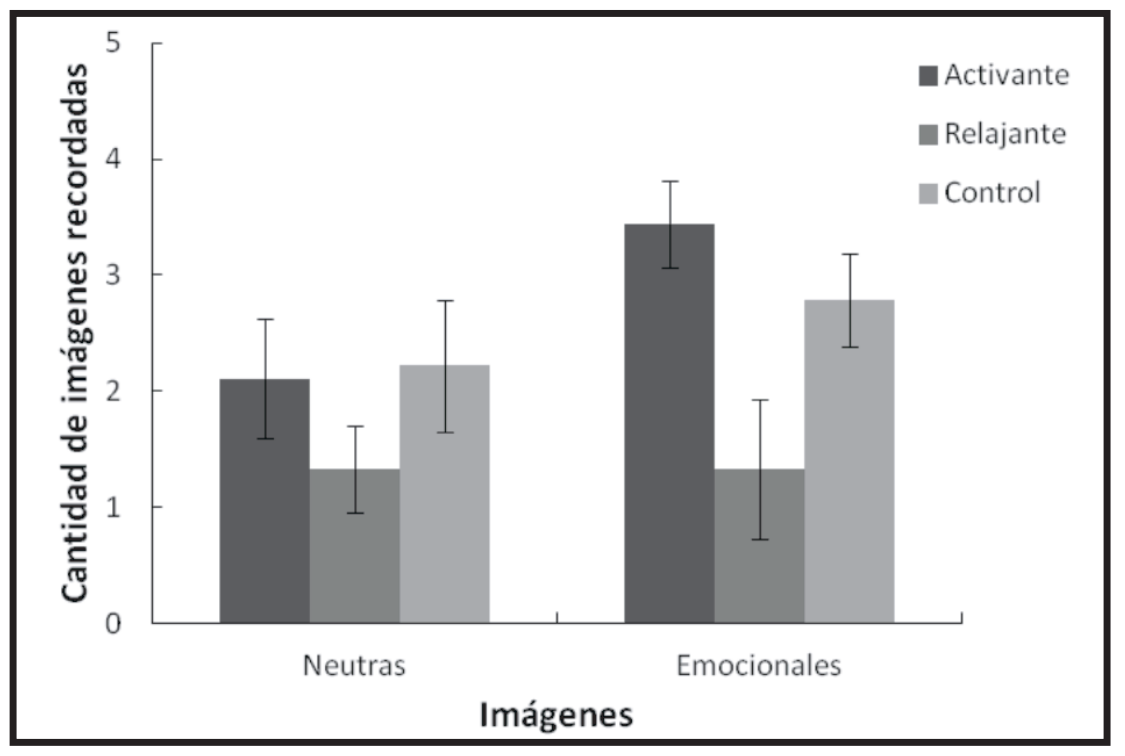

GRÁFICO 3

RECUERDO LIBRE DIFERIDO

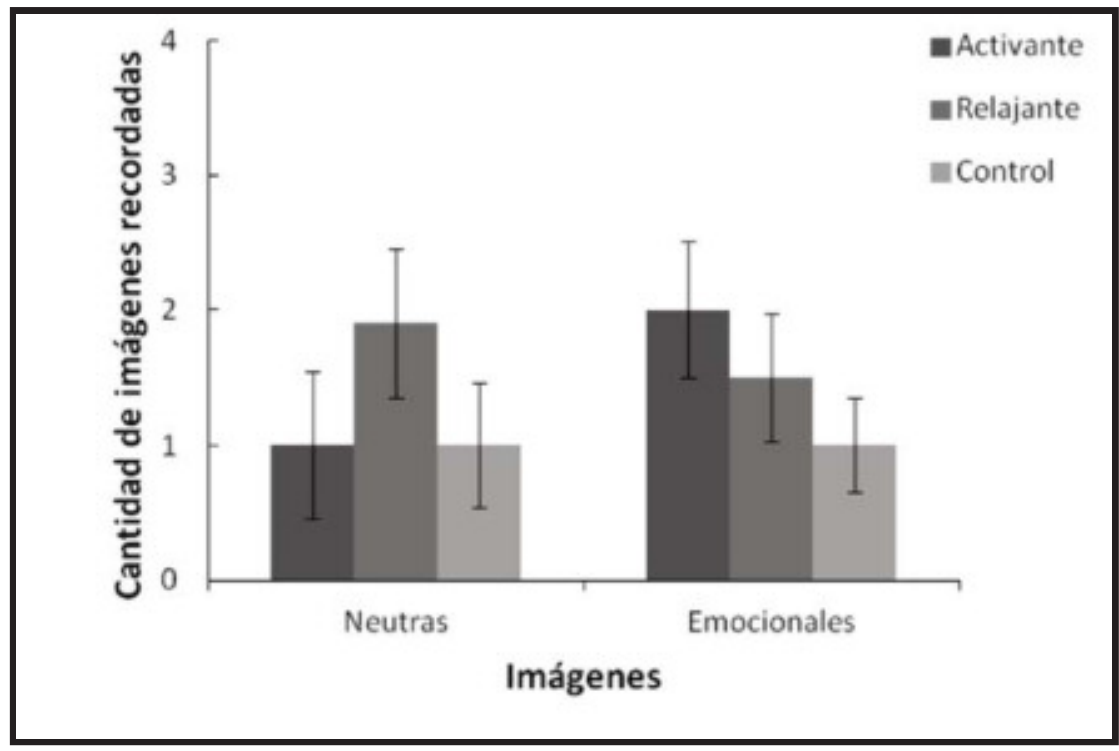




\section{GRÁFICO 4}

RECONOCIMIENTO INMEDIATO DE LAS IMÁGENES

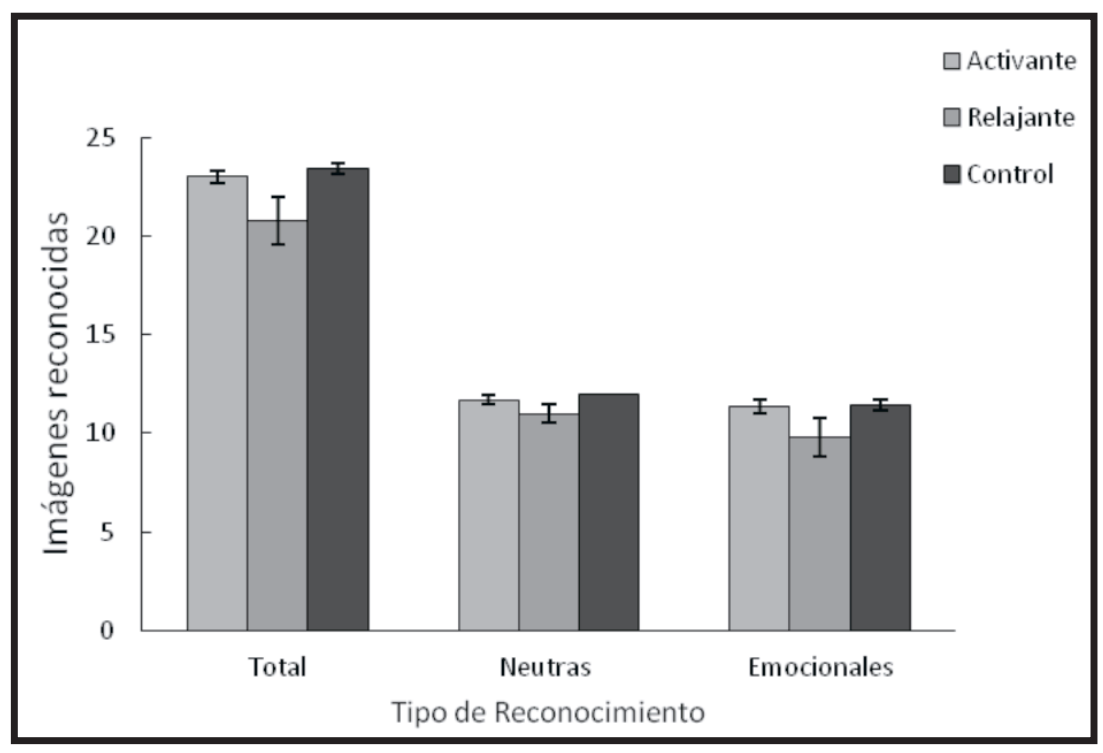

GRÁFICO 5

RECONOCIMIENTO DIFERIDO DE LAS IMÁGENES

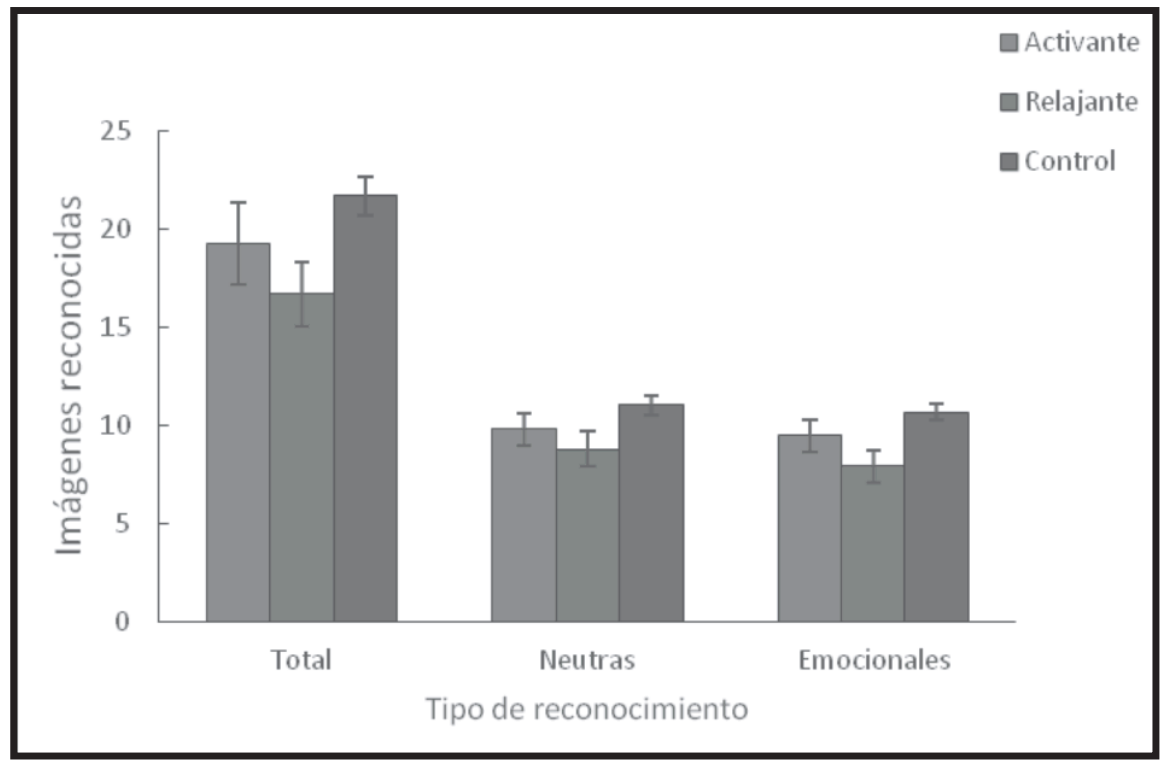




\section{REFERENCIAS BIBLIOGRÁFICAS}

Allegri, R., Ollari, J., Mangone, C., Butman, J., Arizaga, R.L., De Pascale, A. et al. (1999). "Mini Mental State Examination" en la Argentina: Instrucciones para su administración ["Mini Mental State Examination" in Argentina: Instructions for its administration]. Revista Neurológica Argentina, 24(1), 31-35.

Baumgartner, T., Esslen, M. \& Jäncke, L. (2006). From emotion perception to emotion experience: Emotions evoked by pictures and classical music. International Journal of Psychophysiology, 60(1), 34-43.

Bermúdez-Rattoni, F. \& Prado-Alcalá, R.A. (2001). Memoria. ¿En dónde está y cómo se forma? [Memory. Where is it and how does it form?]. México: Trillas.

Blood, A.J. \& Zatorre, R.J. (2001). Intensely pleasurable responses to music correlate with activity in brain regions implicated in reward and emotion. Proceedings of the National Academy of Sciences of the U.S.A., 98(20), 11818-11823.

Bradley, M.M., Greenwald, M.K., Petry, M.C. \& Lang, P.J. (1992). Remembering pictures: Pleasure and arousal in memory. Journal of Experimental Psychology: Learning, Memory, and Cognition, 18(2), 379-390.

Butman, J., Arizaga, R.L., Harris, P., Drake, M., Baumann, D., Pascale, A. et al. (2001). El "Mini-Mental State Examination" en español. Normas para Buenos Aires [The "Mini-Mental State Examination" in Spanish. Standards for Buenos Aires]. Revista Neurológica Argentina, 26(1), 11-15.

Cahill, L. \& Alkire, M. (2003). Epinephrine enhancement of human memory consolidation: Interaction with arousal and encoding. Neurobiology of Learning and Memory, 79, 194-198.

Cahill, L., Gorski, L. \& Le, K. (2003). Enhanced human memory consolidation with post- learning stress: Interaction with the degree of arousal at encoding. Learning \& Memory, 10, 270-274.

Cahill, L. \& McGaugh, J.L. (1995). A novel demonstration of enhanced memory associated with emotional arousal. Consciousness and Cognition, 4, 410-421.

Colden, A., Bruder, M. \& Manstead, A. (2008). Human content in affective-inducing stimuli: A secondary analysis of the international affective picture system. Motivation and Emotion, 32, 260-269.

Denburg, N.L., Buchanan, T.W., Tranel, D. \& Adolphs, R. (2003). Evidence for preserved emotional memory in normal older persons. Emotion, 3(3), 239-253.

Dolcos, F., LaBar, K. S. \& Cabeza, R. (2004). Interaction between the amygdala and the medial temporal lobe memory system predicts better memory for emotional events. Neuron, 42(5), 855-863.

Double, K.L., Halliday, G.M., Kril, J.J., Harasty, J.A., Cullen, K., Brooks, W.S. et al. (1996). Topography of brain atrophy during normal aging and Alzheimer's disease. Neurobiology of Aging, 17, 513-521.

Folstein, M., Folstein, S.E. \& McHugh, P.R. (1975). Mini-Mental State Examination. A practical method for grading the cognitive state of patients for the clinician. Journal of Psychiatric Research, 12(3), 189-198.

Horn, J.L. (1982). The theory of fluid and crystallized intelligence in relation to concepts of cognitive psychology and aging in adulthood. En F.I.M. Craik \& S. Trehub (Eds.), Aging and cognitive processes (pp. 237-278). New York: Plenum Press.

Insausti, R., Insausti, A.M., Sobreviela, M.T., Salinas, A. \& Martinez-Peneuela, J.M. (1998). Human medial temporal lobe in aging: Anatomical basis of memory preservation. Microscience Research and Technology, 43, 8-15. 
Judde, S. \& Rickard, N. (2010). The effect of post-learning presentation of music on long term word list retention. Neurobiology of Learning and Memory, 94, 13-20.

Justel, N. \& Psyrdellis, M. (2014). Novedad y modulación de la memoria: Mecanismos neurobiológicos implicados [Novelty and modulation of memory: Neurobiological mechanisms involved]. Interdisciplinaria, 31(2), 195-211.

Justel, N., Psyrdellis, M. \& Ruetti, E. (2013). Modulación de la memoria emocional: Una revisión de los principales factores que afectan los recuerdos [Modulation of emotional memory. A review of the main factors which influence memories]. Suma Psicológica, 20(2), 163-174. http://dx.doi.org/10.14349/sumapsi2013.1276

Justel, N., Psyrdellis, M. \& Ruetti, E. (2014). Evaluación y modulación de la memoria emocional: Un estudio preliminar [Evaluation and modulation of emotional memory: A preliminary study]. Anuario de Investigaciones de la Facultad de Psicología, XX, 365-368.

Justel, N. \& Rubinstein, W. (2013). La exposición a la música favorece la consolidación de la memoria [Exposure to music favors memory consolidation]. Boletín de Psicología, 109, 73-83.

Justel, N. \& Ruetti, E. (2014). Memoria emocional en adultos mayores: Evaluación del recuerdo de estímulos negativos [Emotional memory in older adults: Negative stimuli recall test]. Cuadernos de Neuropsicología. Panamerican Journal of Neuropsychology, 8(1). http://dx.doi.org/10.7714/cnps/8.1.206

Kensinger, E.A., Growdon, J. H., Brierley, B., Medford, N. \& Corkin, S. (2002). Effects of normal aging and Alzheimer's disease on emotional memory. Emotion, 2(2), 118-134.

Knight, W. \& Rickard, N. (2001). Relaxing music prevents stress-induced increases in subjective anxiety, systolic blood pressure, and heart rate in healthy males and females. Journal of Music Therapy, XXXVIII(4), 254-272.
Koelsch S. (2010). Towards a neural basis of music-evoked emotions. Trends in Cognitive Sciences, 14, 131-137.

Koelsch S., Fritz T, Cramon D.Y.V, Muller K. \& Friederici A.D. (2006). Investigating emotion with music: An fMRI study. Human Brain Mapp, 27, 239-50.

Kreutz, G., Ott, U., Teichmann, D., Osawa, P. \& Vaitl, D. (2008). Using music to induce emotions: Influences of musical preference and absorption. Psychology of Music, 36(1), 101-126.

Lang, P.J., Bradley, M.M. \& Cuthbert, B.N. (2005). International affective picture system (IAPS): Affective ratings of pictures and instruction manual. Technical Report A-6. Gainesville, FL: University of Florida.

Lezak, M.D. (1995). Neuropsychological assessment (3ra. ed.). New York: Oxford University Press.

Raz, N., Briggs, S.D., Marks, W. \& Acker, J.D. (1999). Age-related deficits in generation and manipulation of mental images: II. The role of dorsolateral prefrontal cortex. Psychology and Aging, 14, 436-444.

Rickard, N., Wing Wong, W. \& Velik, L. (2012). Relaxing music counters heightened consolidation of emotional memory. Neurobiology of Learning \& Memory, 97, 220-228.

Ruetti, E., Justel, N. \& Bentosela, M. (2009). Perspectivas clásicas y contemporáneas acerca de la memoria [Classic and contemporaries perspectives about memory]. Suma Psicológica, 16(1), 65-83.

Schaie, K.W. (1996). Intellectual development in adulthood. En J.E. Birren \& K.W. Schaie (Eds.), Handbook of the psychology of aging (pp. 266281). San Diego, CA: Academic Press.

Smith, C.D., Malcein, M., Meurer, K., Schmitt, F.A., Markesberv, W.R. \& Pettigrew, L.C. (1999). MRI temporal lobe volume measures and neuropsychologic function in Alzheimer's disease. Journal of Neuroimaging, 9, 2-9. 
Solís-Vivanco, R. (2012). Modulación emocional de la memoria: Aspectos neurobiológicos [Emotional modulation of memory: Neurobiological aspects]. Archivos de Neurociencias (México, D.F.), 17, 119-128.
Wigram, T., Pedersen, I. \& Bonde, L. (2002). A comprehensive guide to music therapy. Theory, clinical practice, research and training. V. Tosto \& S. Santesteba (Trads.). Londres: Jessica Kingsley Publisher.

Laboratorio de Psicología Experimental y Aplicada (PSEA)

Instituto de Investigaciones Médicas (IDIM)

Consejo Nacional de Investigaciones

Cientificas y Técnicas (CONICET)

Universidad de Buenos Aires (UBA)

Facultad de Psicología

Pontificia Universidad Católica Argentina (UCA)

Ciudad Autónoma de Buenos Aires

Servicio de Neurología

Hospital Interzonal General de Agudos Eva Perón

San Martín - Provincia de Buenos Aires

República Argentina

Fecha de recepción: 23 de octubre de 2014

Fecha de aceptación: 21 de mayo de 2015 